\title{
MAPEAMENTO DE QTLS ASSOCIADOS À PRODUÇÃO DE FRUTOS E SEMENTES EM HÍBRIDOS DE CITRUS SUNKI VS. PONCIRUS TRIFOLIATA ${ }^{1}$
}

\author{
AMAURI SIVIERO ${ }^{2}$, MARIÂNGELA CRISTOFANI ${ }^{2}$, LEONARDO P. BOAVA², MARCOS A. MACHADO²
}

\begin{abstract}
RESUMO - O grupo dos citros apresenta acentuada juvenilidade manifestada pela incapacidade de florescimento, vigor e formação de espinhos. No caso da laranja 'valência', os híbridos de trifoliata, utilizados como porta-enxertos, induzem maior precocidade e produtividade. O número de sementes do fruto (NSF) constitui importante característica da variedade candidata a porta-enxerto de citros. O presente estudo teve como objetivo detectar QTLs associados às características número de frutos por planta (NF) e número de sementes por fruto em uma progênie $\mathrm{F}_{1}$ derivada de um cruzamento entre Citrus sunki e Poncirus trifoliata 'Rubidoux'. Os grupos de ligação (GL) dos parentais foram obtidos usando a estratégia 'pseudotestcross' e marcadores do tipo RAPD. A contagem do número de frutos por planta e o número médio de sementes por fruto foi realizada usando 80 indivíduos da progênie. A detecção dos QTLs foi realizada pelo método de mapeamento por intervalo composto utilizando o programa QTLCartographer. Foram detectados um QTL associado à frutificação e um QTL ligado ao número de sementes situados no GL 4 e GL 5 no mapa de P. trifoliata, respectivamente. Termos para indexação: propagação, melhoramento de citros, marcadores moleculares, frutificação
\end{abstract}

\section{QTL MAPPING LINKED TO FRUIT SET AND SEEDS IN CITRUS SUNKI VS. PONCIRUS TRIFOLIATA HYBRIDS}

ABSTRACT - Citrus group shows juvenility strong due incapacity to flowering, vigor and thorn formation. Trifoliata hybrids used as rootstocks to induce early production and better field for 'Valencia' orange scion. Seeds number per fruit is very important characteristic to citrus rootstocks candidate. The present study has as objective to detect quantitative trait loci (QTL) associated to fruiting and seeds production in $\mathrm{F}_{1}$ progeny obtained of Citrus sunki vs. Poncirus trifoliata cross. Linkage groups (LG) of parents were built by pseudotestcross strategy using RAPD markers. Fruits/plant and seeds/fruit numbers were counting using 80 individuals of progeny. QTL detection was made with composite interval mapping using the QTL Cartographer. QTL linked to fruiting and seed production in LG 4 and LG 5 of the P. trifoliata map, respectively, were detected.

Index terms: propagation, citrus improvement, molecular markers, fruiting

\section{INTRODUÇÃO}

Os citros são uma das mais importantes culturas brasileiras em termos econômico-sociais. O Brasil é o maior produtor e exportador de suco concentrado de laranja do mundo. O Estado de São Paulo concentra $75 \%$ da produção citrícola do Brasil, contando com cerca de 202.000.000 de árvores e ocupando área aproximada de 796.265 ha (Amaro, 1999).

A produção de um grande número de frutos e de sementes do fruto constitui importante característica da variedade candidata a portaenxerto de citros. As espécies cítricas e os gêneros correlatos apresentam comportamento distinto na habilidade de florescimento, frutificação e produção de sementes. Poncirus trifoliata, um importante porta-enxerto para citros, tem hábito típico de planta de clima temperado mostrando diferenças na fisiologia como folhas decíduas no inverno, juvenilidade precoce, indução ao porte ananicante, resistência ao frio, e importantes fontes de genes de resistência a doenças (Spiegel-roy \& Goldschmidt, 1996).

Os principais fatores ligados à produção de frutos cítricos são: polinização, hormônios e o teor de carboidratos da planta (Goldschmidt, 1999). A influência de polinizadores tem estreita ligação com a produção de frutos cítricos (Soares Filho et al., 1995). A frutificação e a época de produção de frutos é influenciada por práticas culturais, aplicação de hormônios e outros produtos (Koller et al., 1999).

O número de sementes de porta-enxerto de citros varia conforme a espécie/cultivar. Moreira (1941) determinou o número de sementes por fruto de diversos porta-enxertos para citros relatando que a 'Lima da Pérsia' (C. limmetoides), P. trifoliata e o pomelo (C. paradisi) produziram 6, 29 e 35 sementes por fruto em média.

O porta-enxerto denominado C. sunki Hort. ex. Tanaka é originário do sudeste da China sendo indicado como porta-enxerto para laranjas, tangerinas e pomelos, possui diversas características desejáveis, como: induz boa formação de copa, apresenta tolerância a tristeza, xiloporose, sorose e declínio, tolerância a solos salinos e a seca. O portaenxerto 'Sunki' apresenta aspectos indesejáveis como: suscetibilidade à gomose e pequeno número de sementes viáveis por fruto (Pompeu Junior, 1991; Castle et al., 1993).
A tangerina 'Sunki' tem a limitação de produzir baixo número de sementes por fruto devido a anormalidades na formação de gametas, limitação natural pelo pequeno número de óvulos ou ausência do polinizador adequado (Castle et al., 1993). Alguns estudos com polinizações controladas indicam que as duas primeiras hipóteses estão descartadas e que o plantio intercalado de polinizadores específicos podem aumentar o número de sementes por fruto de $C$. sunki de 3,2 para 8,1 (Medina Filho et al., 1992). Soares Filho et al. (2000) destacam que a tangerina 'Sunki' é indicada como importante parental feminino em programas de melhoramento de citros via hibridação, pelo alto pegamento, baixa poliembrionia, e elevada frequiência de híbridos, principalmente quando se usa como parental masculino $P$. trifoliata e seus híbridos.

O porta-enxerto $P$. trifoliata (L.) Rafinesque 'Rubidoux', espécie única do gênero, é um genótipo muito usado no Japão, Uruguai e em países de clima temperado sendo indicado para combinações com laranjas, limas ácidas e tangerinas. $P$. trifoliata induz melhor qualidade de suco, é ideal para regiões frias e úmidas, induz baixo vigor reduzindo o porte da copa, facilitando a colheita e o adensamento do pomar e apresenta boas características fitossanitárias como: resistência a Phytophthora spp., nematóides, vírus da tristeza dos citros e a xiloporose. No entanto, possui aspectos negativos como: suscetibilidade ao exocorte, intolerância ao declínio, baixo desenvolvimento em viveiro, intolerância a seca, alta exigência nutricional a apresenta incompatibilidade com a laranja 'Pêra', limões verdadeiros e tangor 'Murcote' (Pompeu Junior, 1991; Castle, et al., 1993).

O mapeamento genético de muitas características de interesse agronômico dos citros tem sido grandemente beneficiado com o advento dos marcadores moleculares permitindo selecionar genótipos superiores para vários caracteres num curto espaço de tempo. A seleção assistida por marcadores moleculares, estratégia que associa marcadores moleculares à locos gênicos importantes para a agricultura e a clonagem de genes são ferramentas úteis em programas de melhoramento de plantas perenes como os citros (Gmitter et al., 1998).

O estudo de locos controladores de características quantitativas (QTLs) associado ao uso de mapas genéticos obtidos por marcadores moleculares permite identificar, mapear e quantificar o efeito dos QTLs. A eficiência na detecção de QTLs depende do número de QTLs, magni- 
tude do seu efeito, herdabilidade da característica, interações entre os genes, tipo e tamanho da população segregante, tamanho do genoma, freqüência de recombinação entre o QTL e o marcador e saturação do mapa (Tanksley, 1993; Young, 1996).

Em programas de melhoramento de espécies perenes como os citros, a estratégia de mapeamento utilizando a técnica 'pseudotestcross' envolve a progênie $\mathrm{F}_{1}$ devido à dificuldade de se obter gerações avançadas. O princípio da técnica do 'pseudotestcross' é que se um parental for heterozigoto para um marcador RAPD e o outro parental apresentar formas alélicas não detectadas (genótipo nulo), a progênie $\mathrm{F}_{1}$ segrega na proporção de 1:1 para ausência e presença do segmento de RAPD detectado. Em resumo, a geração $F_{1}$ obtida do cruzamento entre duas plantas de uma mesma espécie heterozigota se assemelha a uma progênie F2 ou um retrocruzamento nos modelos clássicos de culturas anuais (Grattapaglia \& Sederoff, 1994).

A metodologia de mapeamento por intervalo composto (MIC) utiliza informações de vários marcadores como co-fatores durante a análise e detecção de QTLs, aumentando desta forma a precisão no mapeamento e detecção de QTLs que possam ocorrer em intervalos adjacentes no mesmo grupo de ligação. O MIC prevê um enfoque misto entre o método da máxima verossimilhança e as técnicas de regressão linear múltipla (Zeng, 1993; 1994).

O programa QTLCartographer, desenvolvido por Basten et al. (2000), consiste num conjunto de programas para mapeamento de QTLs a partir de um mapa de ligação genético estabelecendo valores de 'LOD Score' (LOD) para cada região analisada do mapa. A determinação do LOD está em função do número de marcadores avaliados e do comprimento do mapa de ligação. O valor de LOD obtido para um grupo de ligação candidato a conter um QTL deve ser superior ao valor de LOD estipulado para aquela região do mapa. Os picos de LOD indicam a presença de um QTL num segmento do mapa (LIU, 1998).

O presente estudo teve como objetivo detectar locos controladores de características quantitativas (QTLs) associados à produção de frutos e sementes em uma progênie $F_{1}$ obtida do cruzamento entre Citrus sunki e Poncirus trifoliata.

\section{MATERIALEMÉTODOS}

Todos os trabalhos de casa de vegetação e laboratório foram desenvolvidos no Centro de Citricultura 'Sylvio Moreira' do Instituto Agronômico de Campinas -CCSM/IAC, situado em Cordeirópolis, SP. Nos trabalhos foram utilizados híbridos do cruzamento entre $C$. sunki e P. trifoliata 'Rubidoux'

O experimento foi realizado utilizando 82 híbridos obtidos da progênie $\mathrm{F}_{1}$ do cruzamento entre $C$. sunki e $P$. trifoliata. $\mathrm{O}$ cruzamento foi realizado na primavera de 1992. As plantas foram implantadas no campo em 1993/1994. Procedeu-se à contagem do número de frutos por genótipo, número de frutos por planta e o número médio de sementes por fruto das safras de 1998/99 e 1999/2000. No processo de contagem do número de sementes por fruto foi considerada uma amostragem de 25 frutos por planta. Os frutos foram colhidos, abertos no sentido longitudinal e posteriormente a extração e contagem do número de sementes viáveis. Eliminou-se do processo sementes mal formadas e aparentemente inviáveis. O número médio de sementes por fruto foi calculado dividindo-se o número total de sementes pelo total de frutos avaliados de cada genótipo.

Os mapas genéticos contendo os grupos de ligação de $C$. sunki e P. trifoliata 'Rubidoux' utilizados neste trabalho para o mapeamento do caráter enraizamento de estacas foram obtidos de Cristofani et al. (1999). A detecção de QTLs foi realizada pelo mapeamento por intervalo composto segundo Zeng $(1993 ; 1994)$ através do uso do programa QTLCartographer (Basten et al., 2000). As análises de variância foram realizadas pelo programa SAS (Sas institute, 1995). Siviero et al., (2001) usando a mesma população, empregando o QTLCartographer como metodologia de análise de QTLs, identificou quatro QTLs associados à resistência a gomose de Phytophthora dos citros.

\section{RESULTADOSE DISCUSSÃO}

A detecção de QTLs associados ao número de frutos por planta (frutificação) pode ser visualizada pela Figura 1. Na ordenada está disposta a escala dos valores do LOD para cada grupo de ligação analisado. Na abscissa está a representação do grupo de ligação e as distâncias em centiMorgans a partir do telômero esquerdo. A linha ondulante demonstra o resultado da análise realizada pelo programa QTLCartographer. A linha horizontal indica o valor de LOD e o limite de significância estatístico para cada grupo de ligação analisado. A região acima do limite LOD é candidata a conter um QTL. A presença do QTL foi considerada apenas quando foram obtidos picos do LOD para cada grupo de ligação analisando os dois mapas de ligação.

A detecção de QTLs associados ao número de sementes por fruto pode ser visualizada pela Figura 2.

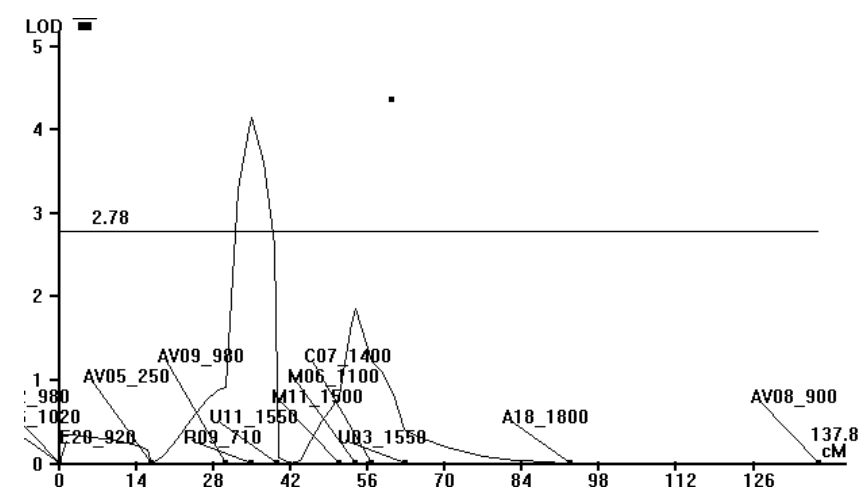

FIGURA 1 - Análise do grupo de ligação IV do mapa de Poncirus trifoliata 'Rubidoux' e a presença de QTL ligado ao número de frutos por planta entre os marcadores AV09_980 e U11_1550 (LOD $>4,0)$.

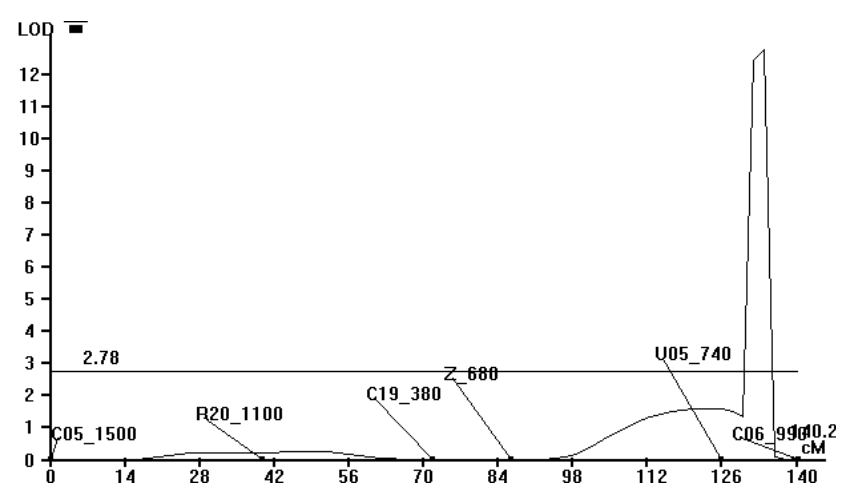

FIGURA 2 - Análise do grupo de ligação V do mapa de Poncirus trifoliata 'Rubidoux' e a presença de QTL associado ao número de sementes por fruto, situado entre os marcadores RAPD, U05_740eC06990(LOD > 12).

Analisando-se a Figura 1 verifica-se a presença de um QTL no mapa de P. trifoliata 'Rubidoux' ligado ao caráter frutificação. A identificação de marcadores moleculares-QTL associados ao caráter frutificação na progênie em estudo, mais precisamente num determinado grupo de ligação de Poncirus trifoliata, indica que esta região é importante na seleção assistida usando marcadores moleculares em materiais visando abreviar o início do processo de produção (precocidade) e maior produtividade. A identificação e detecção de apenas um QTL de expressão maior controlando a produção de frutos por árvore indica que este caráter é oligogênico. Esta constatação diverge do trabalho desenvolvido por Garcia et al. (2000) que trabalhando com o cruzamento entre $C$. volkameriana e $P$. trifoliata, identificaram diversos QTLs associados à produção, tamanho de frutos e número de sementes por fruto, localizados em regiões próximas no genoma. Goldschmidt (1999) especula que a 
produção de frutos cítricos é um caráter de natureza complexa de herança quantitativa. Neste trabalho o QTL associado à frutificação detectado pode possivelmente estar relacionado mais com o fator juvenilidade do que ao fator produtividade.

Analisando-se a Figura 2 verifica-se a presença de um QTL no mapa de $P$. trifoliata 'Rubidoux' associado ao caráter de produção de sementes. Em analogia ao exposto para o fator número de frutos por planta acredita-se que este importante fator de perpetuação da espécie, número de sementes, seja de natureza complexa e controlada por poligenes. A identificação de apenas um QTL de expressão maior associado à produção de sementes é o início do processo de prospecção de marcadores-QTL para este caráter. O pequeno número de indivíduos estudados, a reduzida cobertura do mapa e o uso de somente um tipo de marcador explicam, em parte, o número reduzido de QTLs detectados para caracteres aqui estudados que se acredita serem de herança quantitativa.

\section{CONCLUSÕES}

1. Os híbridos do cruzamento entre Citrus sunki e Poncirus trifoliata segregaram quanto ao caráter número de frutos por planta e número de sementes por fruto, indicando que esta característica tem um componente genético envolvido.

2. Os caracteres frutificação e produção de sementes, nas condições deste experimento, são controlados por um QTL detectado em distintos grupos de ligação de $P$. trifoliata.

\section{REFERÊNCIASBIBLIOGRÁFICAS}

AMARO, A.A. Citricultura. Informações Econômicas, São Paulo, v.29, p.65-74, 1999.

BASTEN, C.J.; WEIR, B.S.; ZENG, Z.B. QTL Carthographer. A reference manual and tutorial for QTL mapping. Raleigh: North Caroline State University, Version 1.14, 2000. 139p.

CASTLE, W.S.; TUCKER, D.P.H.; KREZDORN, A.H.; YOUTSEY, C.O. Rootstocks for Florida citrus: rootstocks selection - The first step to success. 2. ed., Orlando: IFAS, University of Florida, 1993. 92p.

CRISTOFANI, M.; MACHADO, M.A.; GRATTAPAGLIA, D. Genetic linkage maps of Citrus sunki Hort. ex. Tan. and Poncirus trifoliata (L.) Raf. and mapping of citrus tristeza virus resistance gene. Euphytica, Wagenigem, v.109, n.1, p.25-32, 1999.

GARCIA, M.R.; ASINS, M.J.; CARBONELL, E.A. QTL analysis of yield and seed number in Citrus. Theoretical and Applied Genetics, Berlin, v.101, n.3, p.487-493, 2000.

GMITTER, F.; DENG, Z.; MOORE, G.A. Utilization of DNA markers in citrus breeding programs. Fruits, Montpellier, v.53, p.303-306, 1998.
GOLDSCHMIDT, E.E. Carbohydrate supply as a critical factor for Citrus fruit development and productivity. Hortscience, Alexandria, v.34, n.6, p.1020-1024, 1999.

GRATTAPAGLIA, D.; SEDEROFF, R. Genetic linkage maps of Eucalyptus grandees and Eucalyptus urophylla using a pseudo-testcross mapping strategy and RAPD markers, Genetics, New York, v.137, p.170-177. 1994.

KOLLER, O.C.; FERRARI, F.; SCHUARZ, S.F. Frutificação precoce de laranjeiras 'Monte parnaso' com anelagem e pulverizações de acido giberélico e óleo mineral. Pesquisa Agropecuária Brasileira, Brasília, v.34, n.1, p.63-68, 1999.

LIU, B.H. Statistical genomics: linkage, mapping, and QTL analysis. Boca Raton: CRC Press, 1998. 854p.

MEDINA FILHO, H.P.; BORDIGNON, R.; BALLVÉ, R.M.L.; SIQUEIRA, W.J.; CARVALHO, M.L.T. Porta-enxertos híbridos de citros produzidos no Instituto Agronômico de Campinas. Laranja, Cordeirópolis, v.13, n.1, p.777-792, 1992 .

MOREIRA, S. Experiências de cavalos para citrus II. Bragantia, Campinas, v.1, n.8/9, p.524-544, 1941.

POMPEU JUNIOR, J. Porta-enxerto. In: RODRIGUEZ, O.; VIEGAS, F.; POMPEU JUNIOR, J.; AMARO, A.A. Citricultura brasileira. 2.ed., Campinas: Fundação Cargill, 1991, v.1, p. 116-152.

SAS Institute. Release 6.11 of the SAS system for Windows. Raleigh: CRC Press, 1995.437p.

SIVIERO, A.; CRISTOFANI, M.; FURTADO, E.L.; MACHADO, M.A. Detecção de QTLs ligados à resistência de Poncirus trifoliata a gomose. Fitopatologia Brasileira, Fortaleza, v.26. n.1, p.395. 2001.

SOARES FILHO, W.S.; CUNHA SOBRINHO, A.P.; LEE, L.M. Influence of pollinators on fruit set in citrus. Acta Horticulturae, Wageningen, n.403, p.256-265, 1995.

SOARES FILHO, W.S., MOREIRA, C.S., CUNHA, M.A.P., CUNHA SOBRINHO, A.P., PASSOS, O.S. Poliembrionia e freqüência de híbridos em Citrus spp. Pesquisa Agropecuária Brasileira. Brasília, v.35, n.4, p.857-864, 2000.

SPIEGEL-ROY, P.; GOLDSCHMIDT, E.E. Biology of citrus. Cambridge: Cambridge University Press, 1996, 230p.

TANKSLEY, S.D. Mapping poligenes. Annual Review of Genetics. London, v.27, p.205-233, 1993.

YOUNG, N.D. QTL mapping and quantitative disease resistance in plants. Annual Review Phytopathology, Gainsville, v.34, p.479-501. 1996.

ZENG, Z.B. Theoretical basis of precision mapping of quantitative trait loci. Proceedings National Academy Science of Unite States of America, Geneva, p.10972-10976, 1993.

ZENG, Z.B. Precision mapping of quantitative trait loci. Genetics, N. York, v.136, p.1457-1468, 1994. 